\title{
Screening for psychiatric morbidity in an accident and emergency department
}

\author{
GARY BELL, NICK HINDLEY, GITENDRA RAJIYAH \\ \& RACHEL ROSSER
}

Department of Psychiatry, University College and Middlesex School of Medicine, University College London.

\section{SUMMARY}

One hundred and twenty A\&E Department daytime attenders were screened for psychiatric disorder in a two stage procedure. Thirty-three patients were identified as General Health Questionnaire (GHQ) 'cases' of whom 28 agreed to a psychiatric interview using the Clinical Interview Schedule. Twenty-eight GHQ 'non-cases' were also interviewed. A pyschiatric diagnosis was made in 24 patients, 21 of whom were GHQ cases. Patients were more likely to suffer from psychiatric morbidity if the presenting complaint was other than minor trauma. There were trends for psychiatric morbidity to be associated with not being married and living in Bloomsbury Health District (No Fixed Abode or resident) or Northeast London. Sixty-nine percent of cases had a positive past psychiatric history. Ten of 12 cases $(83 \%)$ requiring primary care intervention were not registered with a GP. It is suggested that appropriate intervention would be for A\&E Departments to routinely facilitate such registration. In addition, resources need to be released to make 9 am to $5 \mathrm{pm}$ walk-in psychiatric services commonplace.

\section{INTRODUCTION}

Accident and Emergency (A\&E) Departments provide an important primary care function, especially in inner cities. Whilst a number of studies have focused on undetected psychiatric disorder in medical inpatient, outpatient (Mayou \& Hawton, 1986) and primary care settings (Sireling et al., 1985), little is known about such morbidity among A\&E Department attenders. Medical staff often fail to recognize psychiatric disorder in patients presenting with somatic complaints (Mayou \& Hawton, 1986), yet this is the most common way for psychiatric disorder to

Correspondence: $\operatorname{Dr}$ G. T. Bell, Senior Lecturer, Department of Psychological Medicine, Medical College of St Bartholomew's Hospital, West Smithfield, London EC1A 7BE, U.K. 
present (Murphy, 1989). Identification of psychiatric morbidity in patients presenting to the A\&E Department with somatic complaints may allow for rational attempts at improving the service to these patients. The aims of this study were to evaluate the prevalence and severity of psychiatric morbidity in A\&E daytime attenders presenting with physical complaints, to assess the association of socioeconomic deprivation to such morbidity and to determine the value of self-rated questionnaires in its identification.

\section{PATIENTS AND METHODS}

This study was conducted in the A\&E Department of University College Hospital $(\mathrm{UCH})$. UCH has the only A\&E Department in Bloomsbury, an inner London health district of high socio-economic deprivation (ninth highest in the UK and seventh highest in London according to the Jarman Under Priviledged Area (UPA) Score (Jarman, 1983; Jarman, 1984)) with a large commuter population. All patients aged 16-65 years who walked into the A\&E Department requesting treatment for any physical complaint (primary psychiatric presentation was automatically excluded) were asked to complete the General Health Questionnaire 28 item version (GHQ-28) (Goldberg, 1972; Goldberg 1978) and the Hospital Anxiety and Depression Scale (HAD) (Zigmond \& Snaith, 1983). The GHQ is a self-rated questionnaire designed to screen for psychiatric morbidity, and has been used extensively in general hospital inpatient, outpatient and primary care surveys. GHQ data are reported in this paper; HAD data will be reported separately.

\section{Pilot study}

A one-day pilot study was conducted on a Friday in July from 10am to 12 midnight to assess the feasibility of the study and to identify any methodological problems. Table 1 compares patient's daytime and nightime addresses. Forty out of $70(57 \%)$ patients completed the questionnaires, the proportion during the daytime being greater than at nightime $(62.5 \%$ vs $45.5 \%)$. The study showed that patients seen after $6 \mathrm{pm}$ were (1) fewer in number; (2) more likely to present with psychiatric problems, especially drug and alcohol related; and (3) often accompanied

Table 1. Comparison of daytime and nightime attenders' address.

\begin{tabular}{lcccccc}
\hline & \multicolumn{2}{c}{ Daytime } & \multicolumn{2}{c}{ Nightime } & \multicolumn{2}{c}{ Total } \\
& N & $\%$ & N & \% & N & $\%$ \\
\hline NFA/Bloomsbury & 14 & $(29 \cdot 2)$ & 7 & $(31 \cdot 8)$ & 21 & $(30 \cdot 0)$ \\
Neighbouring & 13 & $(27 \cdot 1)$ & 9 & $(40 \cdot 9)$ & 24 & $(34 \cdot 3)$ \\
$\begin{array}{l}\text { DHAs } \\
\text { Remainder }\end{array}$ & 21 & $(43 \cdot 7)$ & 6 & $(27 \cdot 3)$ & 25 & $(35 \cdot 7)$ \\
Total & 48 & $(100)$ & 22 & $(100)$ & 70 & $(100)$ \\
\hline
\end{tabular}


by a relative which resulted in collaborative completion of the questionnaires despite attempts at separation. Therefore, it was decided to restrict the definitive study to daytime attenders.

\section{Definitive study}

The study was conducted on four weekdays (a Monday and a Friday in August and a Monday and a Tuesday in October) between 9am and $6 \mathrm{pm}$. One hundred and twenty out of $168(71.4 \%)$ completed the questionnaires. Reasons for noncompletion are given in Table 2 . Basic socio-demographic data and details of presenting complaint was recorded on all 168 patients.

All patients who obtained a score of 5 or more on the GHQ-28 $(n=33)$ were asked if they would agree to an interview using the Clinical Interview Schedule (CIS) (Goldberg et al., 1970). The CIS was originally developed to validate the GHQ and has been used in studies of psychiatric morbidity in general medical inpatient populations (Mayou \& Hawton, 1986). Its limited coverage of psychopathology approximates to the greater proportion of psychiatric morbidity found in such populations, although we included additional questions to cover drug and alcohol problems. Twenty-eight patients agreed, three refused and two left the department before interview. Twenty-eight randomly selected patients who obtained a score of four or less on the GHQ-28 were also interviewed. The two interviewers (GB and GR) were blind to patients' GHQ and HAD scores. Details of any past psychiatric history were also obtained at interview. Primary and subsidiary diagnoses together with a global severity rating from zero to four were made. The CIS grading system of severity was as follows: zero $=$ no disorder; one $=$ mild or transient disorder; two $=$ disorder requiring primary care management; three $=$ disorder requiring psychiatric outpatient management; and four $=$ disorder requiring psychiatric inpatient management. If the CIS global severity rating was greater than two, the A\&E officer was informed once he had finished his assessment and before the patient had left the Department, in order for appropriate follow-up arrangements to be made. Patient's A\&E attendance cards were also reviewed for any comments on the mental state. The appropriate pair wise or between group statistical tests of significance were selected for data analysis. Levels of significance were set at 0.05 and for non-significant trends at 0.1 .

Table 2. Reasons for non-participation.

\begin{tabular}{lr}
\hline Too ill & 22 \\
Drunk & 9 \\
No English & 11 \\
Refused & 6 \\
Total & 48 \\
\hline
\end{tabular}




\section{RESULTS}

Sociodemographic data and presenting complaint

Basic socio-demographic data on the 120 patients who completed the GHQ-28 and the HAD are presented in Table. There were no statistically significant differenceso between this group and the 48 patients who did not complete the questionnaires, $\underline{\underline{\underline{\sigma}}}$ except that the latter contained more European visitors. Seventy-four percent of the sample were aged between 16 and 35 years. Males constituted $60 \%$ of the total $\stackrel{\circ}{\circ}$ sample. Seventy-two percent were non-Bloomsbury residents.

A breakdown of presenting complaint is shown in Figure 1. The socio- $\overrightarrow{0}$ demographic variables associated with presenting complaint were sex and ethnicity

Table 3. Socio-demographic data.

\begin{tabular}{|c|c|c|c|c|c|c|}
\hline & \multicolumn{2}{|c|}{ Male } & \multicolumn{2}{|c|}{ Female } & \multicolumn{2}{|c|}{ Total } \\
\hline & $\mathrm{N}$ & $\%$ & $\mathbf{N}$ & $\%$ & $\mathrm{~N}$ & $\%$ \\
\hline Mean age & 29 & & 32 & & $30 \cdot 2$ & \\
\hline \multicolumn{7}{|l|}{ Marital status } \\
\hline - single & 47 & $(65 \cdot 3)$ & 27 & $(56 \cdot 3)$ & 74 & $(61 \cdot 7)$ \\
\hline - married & 14 & $(19.4)$ & 11 & $(22 \cdot 9)$ & 25 & $(20 \cdot 8)$ \\
\hline - widowed & 0 & $(0 \cdot 0)$ & 1 & $(2 \cdot 1)$ & 1 & $(0 \cdot 8)$ \\
\hline - divorced & 2 & $(2 \cdot 8)$ & 5 & $(10 \cdot 4)$ & 7 & $(5 \cdot 8)$ \\
\hline - separated & 0 & $(0 \cdot 0)$ & 4 & $(8 \cdot 3)$ & 4 & (3.3) \\
\hline - unknown & 9 & $(12 \cdot 5)$ & 0 & $(0 \cdot 0)$ & 9 & $(7 \cdot 5)$ \\
\hline \multicolumn{7}{|l|}{ Social class } \\
\hline$-\mathrm{I}$ & 2 & $(2 \cdot 8)$ & 2 & $(4 \cdot 2)$ & 4 & (3.3) \\
\hline- II & 5 & $(6 \cdot 9)$ & 8 & $(16 \cdot 6)$ & 13 & $(\mathbf{1 0 \cdot 8 )}$ \\
\hline - III & 47 & $(65 \cdot 3)$ & 31 & $(64 \cdot 6)$ & 78 & $(65 \cdot 0)$ \\
\hline$-\mathrm{IV}$ & 11 & $(\mathbf{1 5} \cdot 3)$ & 2 & $(4 \cdot 2)$ & 13 & $(10 \cdot 8)$ \\
\hline$-\mathrm{V}$ & 5 & $(6 \cdot 9)$ & 0 & $(0.0)$ & 5 & $(4 \cdot 3)$ \\
\hline - unknown & 2 & $(2 \cdot 8)$ & 5 & $(10 \cdot 4)$ & 7 & $(5 \cdot 8)$ \\
\hline \multicolumn{7}{|l|}{ Employment status } \\
\hline - employed & 63 & $(87 \cdot 5)$ & 33 & $(68 \cdot 8)$ & 96 & $(80 \cdot 0)$ \\
\hline - unemployed & 7 & $(9.7)$ & 10 & $(20 \cdot 8)$ & 17 & $(14 \cdot 2)$ \\
\hline - unknown & 2 & $(2 \cdot 8)$ & 5 & $(10 \cdot 4)$ & 7 & $(5 \cdot 8)$ \\
\hline \multicolumn{7}{|l|}{ Address } \\
\hline$-\mathrm{NFA}$ & 1 & $(1 \cdot 4)$ & 1 & $(2 \cdot 1)$ & 2 & $(1 \cdot 7)$ \\
\hline - Bloomsbury & 18 & $(25 \cdot 0)$ & 14 & $(29 \cdot 2)$ & 32 & $(26 \cdot 7)$ \\
\hline - North East Thames & 23 & $(31 \cdot 9)$ & 17 & $(35 \cdot 4)$ & 40 & $(33 \cdot 2)$ \\
\hline - Other London & 24 & $(33 \cdot 3)$ & 8 & $(16 \cdot 6)$ & 32 & $(26 \cdot 7)$ \\
\hline - Other UK & 5 & $(7 \cdot 0)$ & 7 & $(14 \cdot 6)$ & 12 & $(\mathbf{1 0 \cdot 0 )}$ \\
\hline - Abroad & 1 & $(1 \cdot 4)$ & 1 & $(2 \cdot 1)$ & 2 & $(1 \cdot 7)$ \\
\hline \multicolumn{7}{|l|}{ Ethnicity } \\
\hline - white British & 64 & $(88 \cdot 9)$ & 40 & $(83 \cdot 3)$ & 104 & $(86 \cdot 7)$ \\
\hline - white European & 4 & $(5 \cdot 5)$ & 4 & $(8 \cdot 3)$ & 8 & $(6 \cdot 7)$ \\
\hline - Afro-caribbean & 1 & $(1 \cdot 4)$ & 2 & $(4 \cdot 2)$ & 3 & $(2 \cdot 5)$ \\
\hline - Asian & 1 & $(1 \cdot 4)$ & 0 & $(0 \cdot 0)$ & 1 & $(0 \cdot 8)$ \\
\hline - Middle Eastern & 1 & $(1 \cdot 4)$ & 0 & $(0 \cdot 0)$ & 1 & $(0 \cdot 8)$ \\
\hline - North American & 1 & $(1 \cdot 4)$ & 2 & $(4 \cdot 2)$ & 3 & $(2 \cdot 5)$ \\
\hline Total & 72 & $(100)$ & 48 & (100) & 120 & $(100)$ \\
\hline
\end{tabular}




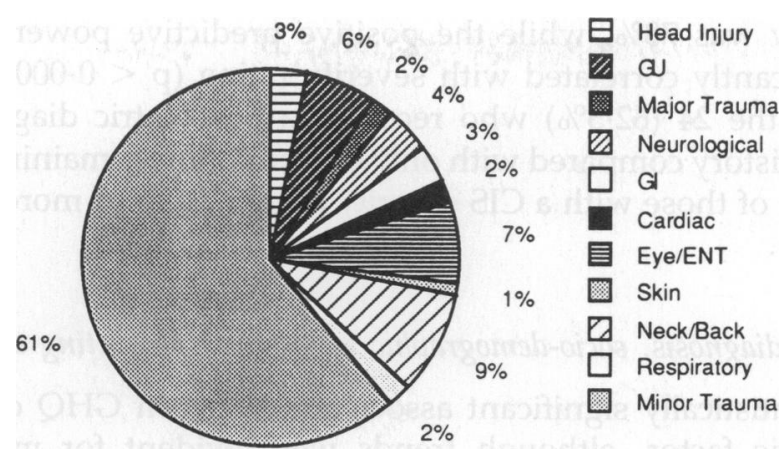

Fig. 1. Presenting complaint.

with a trend for address. Females were less likely to present with minor trauma $(p<0.005)$, as were ethnic groups other than white British $(p<0.03)$. Approximately $51 \%$ of Bloomsbury and NE London residents presented with minor trauma whereas, for those with other addresses, this, not surprisingly, rose to $67 \%$ $(\mathrm{p}<0 \cdot 1)$.

\section{GHQ and psychiatric diagnosis}

Using the standard threshold score of $4 / 5,33$ patients $(27.5 \%)$ were identified as GHQ 'cases' and 28 of these agreed to interview along with 28 randomly selected GHQ 'non cases'. Of the 56 patients interviewed, 24 were diagnosed as suffering from a psychiatric disorder, although in one-third of these the disorder was regarded as mild and/or transient. Three patients were diagnosed as suffering from a depressive disorder, 12 had an anxiety state, eight a mixed anxiety/ depressive disorder and one had a phobic anxiety disorder. Subsidiary diagnoses of alcohol abuse and personality disorder were made in one and three patients respectively. The predictive power of the GHQ and the severity rating of the disorders diagnosed are shown in Table 4 . The sensitivity of the GHQ was $87.5 \%$

Table 4. GHQ caseness and psychiatric diagnosis.

\begin{tabular}{|c|c|c|c|c|}
\hline & \multicolumn{4}{|c|}{ Severity rating on CIS } \\
\hline & 1 & 2 & 3 & 4 \\
\hline \multirow{2}{*}{$28 \mathrm{GHQ}+<$} & 5 & 12 & 4 & 0 \\
\hline & - & - & - & - \\
\hline \multirow{2}{*}{$28 \mathrm{GHQ}-\longleftarrow_{25}^{3}$ 'non cases' } & 3 & 0 & 0 & 0 \\
\hline & - & - & - & - \\
\hline Total Cases $=24$ & 8 & 12 & 4 & 0 \\
\hline
\end{tabular}

$\mathrm{X} 2=23 \cdot 6,1 \mathrm{df}, \mathrm{p}<0.0001$ 
and its specificity was $78 \%$, while the positive predictive power was $75 \%$. GHQ score was significantly correlated with severity rating $(p<0.0001)$.

Fifteen out of the $24(62.5 \%)$ who received a psychiatric diagnosis also had a past psychiatric history compared with only one out of the remaining 32 interviewed $(p<0.0001)$, and of those with a CIS severity score of two or more, this figure rose to $69 \%(11$ of 16$)$.

\section{GHQ, psychiatric diagnosis, socio-demographic factors and presenting complaint}

There was no statistically significant association between GHQ caseness and any $\stackrel{\infty}{\overrightarrow{0}}$ socio-demographic factor, although trends were evident for marital status and $\overrightarrow{\vec{H}}$ address. Approximately $42 \%$ of those divorced, widowed or separated were GHQ cases. This fell to $29 \%$ for single subjects and to $20 \%$ for those who were married. This trend was similarly reflected in their mean GHQ scores $(5.4,3.8$, and 3.5. respectively). Table 5 shows GHQ caseness and mean GHQ score by address. Whilst there was a non-significant trend for Bloomsbury and Northeast London $\vec{f}$ residents to be GHQ 'cases' $(p<0 \cdot 1)$, they are much more likely to receive a higher severity rating at interview $(p<0 \cdot 05)$. Patients presenting with complaints other than minor trauma were much more likely to be GHQ 'cases' $(p<0.02)$ and $\mathcal{D}_{\mathbb{D}}$ were more likely to receive a psychiatric diagnosis; however, unlike GHQ caseness, this was a non-significant trend $(p<0 \cdot 1)$.

\section{Detection of psychiatric morbidity and referrals}

None of the 120 patients included in the study were referred by the A\&E offic for psychiatric assessment. In four patients the CIS global severity score was three and so the A\&E officer was informed and appropriate follow-up arrangements made. Ten of the 12 patients $(83 \%)$ given a severity score of two lived in inner London yet only two were registered with GPs. Most of this group were young men. Of the four patients given a severity score of three, two had GPs and were receiving psychiatric treatment. The remaining two were neither registered with a GP nor were they receiving psychiatric treatment. A\&E record cards for all 120

Table 5. GHQ caseness and address.

\begin{tabular}{|c|c|c|c|c|c|c|c|c|c|}
\hline & \multicolumn{2}{|c|}{ Cases } & \multirow{2}{*}{$\begin{array}{l}\text { GHQ } \\
\text { Mean }\end{array}$} & \multicolumn{2}{|c|}{ Non Cases } & \multirow{2}{*}{$\begin{array}{l}\text { GHQ } \\
\text { Mean }\end{array}$} & \multicolumn{2}{|c|}{ Total } & \multirow{2}{*}{$\begin{array}{l}\text { GHQ } \\
\text { Mean }\end{array}$} \\
\hline & $\mathrm{N}$ & $\%$ & & $\mathrm{~N}$ & $\%$ & & $\mathrm{~N}$ & $\%$ & \\
\hline $\begin{array}{l}\text { NFA/ } \\
\text { Bloomsbury }\end{array}$ & 10 & $(30 \cdot 3)$ & $10 \cdot 1$ & 25 & $(28 \cdot 7)$ & 1.4 & 34 & $(28 \cdot 3)$ & $4 \cdot 0$ \\
\hline NE London & 14 & $(42 \cdot 4)$ & $11 \cdot 2$ & 26 & $(29.9)$ & 1.5 & 40 & $(33 \cdot 3)$ & 4.9 \\
\hline Other London & 7 & $(21 \cdot 2)$ & $11 \cdot 0$ & 24 & $(27 \cdot 6)$ & $1 \cdot 3$ & 32 & $(26 \cdot 7)$ & 3.4 \\
\hline $\begin{array}{l}\text { Other UK/ } \\
\text { Abroad }\end{array}$ & 2 & $(6 \cdot 0)$ & $12 \cdot 0$ & 12 & $(13 \cdot 8)$ & $1 \cdot 7$ & 14 & $(11 \cdot 7)$ & 3.2 \\
\hline Total & 33 & $(100)$ & $10 \cdot 9$ & 87 & $(100)$ & 1.4 & 120 & $(100)$ & $4 \cdot 0$ \\
\hline
\end{tabular}


patients were reviewed and on only one of the above four, who happened to be registered with a GP, was there a comment about the mental state.

\section{DISCUSSION}

This study confirms that mild to moderate degrees of psychiatric morbidity, predominantly anxiety and depression, have a similar prevalence in A\&E attenders to that identified in primary care studies. Whilst Jarman's UPA score of social deprivation was not as strongly predictive of psychiatric morbidity as expected, trends were certainly evident for marital status (widowed, divorced and separated rather than single) and living in Bloomsbury (NFA or resident) and Northeast London. In addition, the severity rating of psychiatric morbidity in these areas was higher. These findings are in contrast to our study of A\&E admissions (Bell et al. 1990) in which strong associations between psychiatric morbidity and a number of socio-demographic factors were demonstrated. This may well be a reflection of the different levels of physical morbidity in the two samples.

The study also confirms that psychiatric morbidity in A\&E attenders goes largely under-recorded (and probably undetected) by medical staff. Whilst the GHQ proved an acceptable and reliable method of identifying psychiatric morbidity in an A\&E setting, routine administration in a busy A\&E Department is likely to be impractical. Asking about past psychiatric history would have detected $60 \%$ of all cases requiring intervention, but only half of the more severe cases. Whilst the level of psychiatric morbidity in an inner urban A\&E Department is high, the greater proportion can be easily detected and contained in a primary care setting. One model is an emergency walk-in psychiatric clinic in contiguity with A\&E. Another is close collaboration with local GPs. In particular, a mechanism to register attenders immediately with GPs is a logical solution. However, this might prove controversial as many GPs prefer a more personal approach to accpeting new patients onto their list. At the very least a list of local GPs with vacancies should be available in A\&E Departments. Patients could then be given the name of a GP to approach together with a standard letter of introduction.

\section{ACKNOWLEDGEMENTS}

We gratefully acknowledge the assistance of Dr Howard Baderman, Mrs Amanda Furneaux and the medical and nursing staff in the A\&E Department at UCH.

\section{REFERENCES}

Bell, G., Reinstein, D., Rajiyah, G \& Rosser, R. 1990 Psychiatric screening and intervention in accident and emergency ward admissions (submitted for publication). 
Goldberg, D. P., Cooper, A. B., Eastwood, M. R., Kedward, H. B. \& Shepherd, M. (1970) A standardized interview suitable for use in community surveys. British Journal of Preventative and Social Mediciné 24, 18-24.

Goldberg, D. (1972) The detection of psychiatric illness by questionnaire. Maudsley Monograph No. 21, Oxford University Press, Oxford.

Goldberg, D. (1978) Manual of the General Health Questionnaire. Windsor:NFER-Nelson, London. Jarman, B. (1983) Identification of underpriviledged areas. British Medical Journal, 286, 1705-9.

Jarman, B. (1984) Underpriviledged areas: validation and distribution of scores. British Medical Journal 289, 1587-92.

Mayou, R. \& Hawton, K. (1986) Psychiatric disorder in the general hospital. British Journal of Psychiatry? 149, $172-190$.

Murphy, M. (1989) Somatisation: embodying the problem. British Medical Journal, 298, 1331-2.

Sireling, L. I., Paykel, E. S., Freeling, P., Rao, B. M. \& Patel, S. P. (1985) Depression in general practice: Case thresholds and diagnosis. British Journal of Psychiatry, 147, 113-9.

Zigmond, A. S. \& Snaith, R. P. (1983) The hospital anxiety and depression scale. Acta Psychiatricos Scandinavica, 67, 361-70. 